\title{
Teachers' oral corrective feedback and learners' uptake in high school CLIL and EFL classrooms
}

\author{
Ruth Milla \\ Universidad del País Vasco (UPV/EHU) \\ Departamento de Didáctica de la Lengua y la Literatura \\ ruth.milla@ehu.eus \\ María del Pilar García Mayo \\ Universidad del País Vasco (UPV/EHU)
}

Departamento de Filología Inglesa y Alemana y de Traducción e Interpretación maria.pilar@garciamayo@ehu.eus

\begin{abstract}
Oral corrective feedback (OCF) has been reported to be affected by several factors such as learners' age, level of proficiency or the OCF types provided by the teacher. However, little research has been carried out on the variable learning context, even though OCF and uptake vary in rates and types in second language (SL) and foreign language (FL) settings. Moreover, OCF has been clearly under-researched in classrooms that follow a content and language integrated learning (CLIL) approach. As CLIL programs are being widely implemented mainly in European settings and differences in context characteristics suggest variations in OCF and learners' uptake, the present study aimed to compare the recorded classroom interaction data (22 hours 43 minutes) from an intact class of learners $(\mathrm{N}=26)$ in their last year of secondary education (age 17-18), attending the lessons of an English as a FL (EFL) teacher and a Business Studies (CLIL) teacher. Findings show significant differences as to the proportion and OCF types used, as well as different learners' behavior regarding the rates of uptake and repair and the uptake after the use of recasts. Pedagogical implications are offered as to how to maximize the potential benefits of OCF in FL classrooms.
\end{abstract}

Keywords: Oral corrective feedback, corrective feedback episodes, EFL, CLIL, learning context

\section{Resumen}

Estudios previos han hallado que la retroalimentación correctiva oral (RCO) puede variar dependiendo de factores tales como la edad y el nivel de conocimiento de lengua de los aprendices o los tipos de RCO que facilita el profesor. Sin embargo, existe 
escasa investigación sobre la variable del contexto de aprendizaje, aunque la RCO y la respuesta de los aprendices difiere en cantidad y tipo en contextos de segunda lengua y contextos de lengua extranjera (LE). Además, la RCO apenas ha sido investigada en aulas que siguen un enfoque de aprendizaje integrado de contenido y lengua extranjera (AICLE). Debido a que los programas de AICLE se están implementando ampliamente en contextos europeos y que las diferencias entre los contextos sugieren posibles variaciones en cuanto a la RCO y la respuesta de los aprendices, este trabajo tiene como objetivo comparar la interacción oral grabada ( 22 horas 43 minutos) en un aula intacta $(\mathrm{N}=26)$ de segundo curso de bachillerato (edad=17-18) en las clases de inglés como LE con otra de estudios empresariales (AICLE). Los resultados muestran diferencias significativas en cuanto a los tipos de RCO utilizados y la respuesta de los aprendices ante las reformulaciones. Se presentan implicaciones pedagógicas relativas a cómo obtener el máximo beneficio de la RCO en aulas de LE.

Palabras clave: Retroalimentación oral, episodios de retroalimentación oral, ILE, AICLE, contexto de aprendizaje.

\section{Introduction}

Oral corrective feedback (OCF) has been defined as "a reactive type of formfocused instruction which is considered to be effective in promoting noticing and thus conducive to learning" (Yang \& Lyster, 2010: 237). OCF is a pedagogical technique that has been claimed to be beneficial for the process of second language acquisition (SLA) (Russell \& Spada, 2006; Sheen, 2011). This oral corrective technique is part of what has been termed as corrective feedback episodes (CFE). We have chosen the term CFE as it is the most frequently used in the literature (Lyster, Saito \& Sato, 2013; Mackey, Gass \& McDonough, 2000) after Lyster \& Ranta's (1997) seminal study. Typically, CFEs consist of three moves: Error, OCF and Uptake. Example (1), which belongs to the database of the present study, as all the examples in this paper, illustrates them:

(1) Learner: (...) there *haven't been any victims.

Teacher: there weren't any victims. You are talking about the past, right? There weren't any victims. There weren't any. What other word do you have for victim?

Learner: but was today!

Teacher: yes, but the tense that you have is past: "were involved". It is not: "there has been an accident" and then you can use the present. No, the past. Another word for victims? 
A CFE consists of three moves: the first is the error that the learner produces within oral interaction, in example 1 an error having to do with the use of tenses. The second turn represents the teacher's OCF move, which can take different forms. In a seminal study on OCF, Lyster \& Ranta (1997), identified six types of OCF: recasts and explicit correction on the one hand, which have been grouped into a larger category referred to as reformulations since they offer the target form, and, on the other, repetition, clarification requests, elicitation and metalinguistic cues, which have been termed prompts (Lyster 2002, et passim) and try to elicit learners' self-repair. Of all these, recasts are the most frequently used types and they have been further divided into two different types: conversational and didactic (Sheen, 2006). Conversational recasts are more implicit and less direct, as teachers use longer sentences to reformulate the error and, therefore, they tend to be a less salient type of OCF. Didactic recasts, on the contrary, are more explicit and direct, and teachers use shorter reformulations of the erroneous utterance and isolate the repaired form to make it more visible. Recasts of this latter type become more salient and more easily perceived by the learners and they typically appear in form-oriented lessons. In example 1 , the teacher reformulates the erroneous verb tense and provides the target form, using an explicit correction move. Finally, the third move corresponds to the learner's reaction to the OCF provided, which is referred to as uptake. The uptake move does not appear in all CFEs and, when it does, it can be of several types: the learner may fail to repair the error (the 'needs repair' category in Lyster \& Ranta, 1997), as in (1) above; the error is repaired by the learner ('self-repair') or by another learner ('peer-repair'). In (1) one can find yet another move, which consists of further OCF in the form of a metalinguistic explanation by the teacher, who then continues with the topic of the lesson.

OCF is a topic that has been explored widely in the field of SLA (Nassaji \& Kartchava, forthcoming). Different factors have been considered in previous studies, such as learners' individual differences (ID) or the type of OCF that could be more appropriate to address different types of errors (Kartchava \& Ammar, 2014). Regarding the former, learners' age (Oliver \& Grote, 2010; Panova \& Lyster, 2002), learners' beliefs (Kartchava, 2016; Yang, 2016) and proficiency level (Ammar \& Spada, 2006; $\mathrm{Li}, 2014$ ) have been reported to have an impact on learners' response to oral corrections. As for the latter, research has reported the predominance of recasts, with the exception of OCF in high school classrooms, where prompts have been claimed to be more frequent (Brown, 2016). In terms of their effectiveness, both recasts (Goo \& Mackey, 2013; Long, 2015) and prompts have been found to lead to successful uptake and repair, depending on variables such as error type. Thus, prompts have been found to be more effective for grammar errors while recasts appear to lead to higher rates of uptake when used for pronunciation or lexical errors (Bryfonski \& Ma 2020, Gurzynski-Weiss, 2010; Saito, 2013). In addition, a balanced and tailored provision of 
types has been recommended (Li, 2014; Li, 2018; Lyster \& Mori, 2006; Saito \& Lyster, 2012).

The variable instructional context, i.e., the type of learning setting, has been acknowledged to affect learners' reaction to OCF in general and their uptake of the different OCF types (Mackey \& Goo, 2007; Sheen, 2004) but it has been very scarcely researched. Although previous studies have explored oral CFEs in SL (Kartchava \& Ammar, 2014a; Loewen, 2004; Lyster, 2004) and foreign language (FL) settings (Goo, 2012; Havranek \& Cesnik, 2001; Yilmaz, 2012) only a handful of studies have established comparisons between the two (Milla \& García Mayo, 2014; Llinares \& Lyster, 2014; Lochtman, 2007; Lyster \& Mori, 2006; Sheen, 2004), with findings showing relevant differences between the two contexts.

The aim of the present study is to investigate OCF in two different settings, a traditional English as a Foreign Language (EFL) classroom and a Content and Language Integrated (CLIL) classroom, in order to assess the extent to which instructional context has an impact on CFEs and learner uptake. We will adopt the definition of CLIL provided by Dalton-Puffer $(2011: 183)$ as an educational approach where "[...] curricular content is taught through the medium of a FL [foreign language] typically to learners participating in some form of mainstream education at the primary, secondary or tertiary level". In what follows we first provide a summary of the studies that have compared OCF in different language contexts, to then move onto the actual details of the current study, its major findings and implications.

\section{Literature review}

To the best of our knowledge, Sheen (2004) was the first study that compared CFEs in different learning contexts. She examined four different classroom settings: French immersion (FI) and English as a Second Language (ESL) in Canada, ESL in New Zealand and EFL in Korea and focused on recasts (reformulations of the erroneous utterance by providing the target form) due to the small proportion of the rest of OCF types in her database. Her findings showed differences as to OCF provision and uptake: the use of recasts, although high in all settings, was significantly higher in New Zealand and Korean classrooms than in FI and ESL in Canada. Significant differences were also found between the amount of recasts in Korean EFL and New Zealand ESL settings.

In addition to the differences in OCF provision, the rate of uptake after recasts and subsequent repair was found to be higher in the Korean EFL and New Zealand ESL contexts than in Canadian ESL and immersion classrooms. Sheen attributes 
this difference in uptake to the learners' orientation to form rather than meaning in Korean EFL and New Zealand ESL, which consequently led to greater noticing of this OCF type. The fact that an ESL setting is oriented to form and not to meaning contrasts with other SL contexts, typically oriented to meaning. This difference might be related to the fact that this was an intensive course with a native speaker teacher and the learners were somewhat older. Sheen (2004) calls for more research on different topics, such as the impact of contextual factors on OCF patterns and learner uptake.

Lyster \& Mori (2006) also considered how instructional setting could be a relevant factor in OCF provision. They observed and recorded intact lessons in two different learning settings at the elementary-school level. There were 18.3 audio-recorded hours of FI lessons for English speaking learners in Canada with French as a Second Language (FSL), taken from Lyster \& Ranta's (1997) seminal study, and 14.8 hours of video recordings of Japanese immersion (JI) for English speakers in the USA, that is, Japanese as a foreign language (JFL), taken from the data reported on in Mori (2002).

Lyster \& Mori (2006) analysed the lessons with Part A of the communicative orientation of language teaching (COLT) coding scheme used by Spada \& Fröhlich (1995). They found that FSL lessons had a more experiential orientation and the focus of the lesson was generally on meaning and rarely on form, while JFL lessons had a more analytic orientation and the focus of the lesson was predominantly on form. The authors then compared CFEs in each of the two settings. Their analysis revealed that the proportion of errors corrected by the teachers was similar (67\% and 61\%) and that OCF types were similarly used across the two contexts, with recasts being the predominant type (54\% and $65 \%$ of all OCF moves), prompts in a smaller proportion (38\% and 26\%) and explicit correction relatively infrequent (7\% and 9\%).

However, findings related to uptake revealed differences: rates of uptake and repair were higher in JFL than in FSL. Uptake of the different types varied with the largest amount coming from prompts in the FSL classrooms (62\%) and from recasts in the Japanese language learning setting (61\%). Similarly, the proportion of repair was reversed, the highest amount of repair after prompts being found in FSL (53\%) and after recasts in JFL (68\%). Uptake and repair following explicit correction moves was similarly small in both settings, less than $10 \%$.

Based on these findings, the authors proposed the Counterbalance Hypothesis $(\mathrm{CH})$, which states that:

[...] instructional activities and interactional feedback that act as a counterbalance to a classroom's predominant communicative orientation are likely to prove more effective than instructional activities and interactional feedback that are congruent with its predominant communicative orientation. (Lyster E⿱乛龰 Mori, 2006: 269) 
Thus, the teachers in the meaning-focused lessons of the FSL context obtained more learners' uptake with the use of form-focused teaching techniques, such as prompts. On the other hand, in the JFL classrooms, which were found to be more oriented to form, more meaning-focused or implicit types resulted in larger rates of uptake and repair due to learners' awareness of OCF in these settings. The authors explain that the COLT coding scheme helps to recognize the orientation of a given classroom to form or to meaning. The analysis of the activities can help researchers to recognize the learners' orientation, which, in turn, seems to predict their ability to perceive and use the different OCF types. Therefore, the authors advocate for a balanced provision of OCF, using different types in order for the learners to be able to notice them. They also call for more 'fine-grained' classroom research where the TL is the same in all the settings and where classrooms with FL instruction are compared with immersion settings.

Lochtman (2007) is another example of a comparative study. The data were gathered in German as a Foreign Language (GFL) classrooms (Lochtman, 2002) and in FSL classrooms (Lyster \& Ranta, 1997). The comparison revealed differences in OCF provision: teachers in FL settings tended to offer prompts while SL teachers preferred to use recasts. As for uptake, similar results were found, with higher rates in response to prompts in both settings but in GFL recasts also obtained remarkable rates of repair. Therefore, Lochtman's (2007) results were in line with those of Lyster $\&$ Mori's (2006) study regarding the finding that instructional context influences the three moves of CFEs.

There is a language learning setting that has been underresearched as far as OCF is concerned, namely, the CLIL setting. CLIL occurs typically in FL contexts and, although it derives from immersion programs in Canada, it includes not only the communicative use of the language, but also skills, contents and competences, with a holistic vision of the language. CLIL teachers are not native speakers of the TL or language teachers, but subject teachers, who normally plan their content lessons alongside the traditional FL lessons taught by language experts. Nevertheless, as CLIL is an umbrella term and has been implemented profusely in primary, secondary and university levels throughout Europe (Pérez Cañado, 2012), there are multiple types of programs that can be found under this approach, as we will see in what follows. All in all, CLIL lessons differ from FL lessons since the focus has moved from language form towards content. In this sense, OCF can be hypothesized to take different forms and lead to different rates of learners' uptake.

A recent study comparing FSL in Canada, JFL in the USA and CLIL classrooms in Spain was carried out by Llinares \& Lyster (2014). The researchers used data from Lyster \& Mori's (2006) FSL and JFL classrooms and included a CLIL context, which, 
as mentioned above, involves an integration of form and meaning -language and subject matter- and more hours of exposure to the TL. In this study, CLIL learners, primary school children, had Spanish as their L1 and were enrolled in a bilingual program, with English as the TL. Based on Lyster \& Mori's (2006) comparison of two different immersion classrooms, Llinares \& Lyster (2014) performed a three-way analysis of CFEs examining the frequency and distribution of OCF types as well as repair and uptake of those types and tried to identify the factors that contribute to similarities or differences across the instructional settings.

Llinares \& Lyster (2014) reported that OCF types occurred in a similar proportion in the three settings: recasts were the most frequently used type, followed by prompts and the least used type was explicit correction. As for uptake, the pattern was reversed: higher uptake after recasts was found in CLIL and JFL while FSL learners showed more uptake after prompts. Recasts were much more effective - in terms of repair- in CLIL classrooms, with the opposite happening in FSL classrooms. In JFL, similarly high rates of repair were found for recasts, prompts and explicit correction. Finally, as for recast type, the researchers use the distinction between conversational and didactic recasts (Sheen, 2006), mentioned above. In Llinares \& Lyster (2014) study, CLIL and JFL teachers used a greater amount of didactic recasts while FSL teachers preferred conversational recasts, a feature that the authors present as a possible explanation for the differences in uptake and repair: the explicitness of didactic recasts may favour the learners' awareness of the correction and, in turn, increase the effectiveness of this OCF move.

Llinares \& Lyster (2014) examined classroom differences and reported that interaction in CLIL and JFL shared more characteristics than JFL and FSL, which were both termed as immersion contexts by Lyster \& Mori (2006). Llinares \& Lyster (2014) explain that this finding has to do with the fact that, as there are different types of CLIL programs (Lasagabaster \& Sierra, 2010), immersion programs differ from one another as well (Tedick \& Cammarata, 2012). Thus, in each of the contexts, teachers' beliefs and previous experience shape OCF patterns and the type of instruction seems to influence learners' noticing of OCF as well. The authors consider it interesting to explore CFEs in secondary level classrooms, where CLIL teachers' background is different, since they are subject matter specialists and have no specific training as language teachers. Llinares \& Lyster (2014) call for further research on the effect of the instructional context variable on OCF patterns.

In a recent meta-analysis, Brown (2016) considered the teachers' background in relation to their provision of CF. The author explains that teachers with more L2 training tended to provide more prompts than recasts and pay more attention to lexical than to phonological errors. Therefore, it seems interesting to compare the 
behavior regarding the OCF of teachers with previous linguistic training and those who are content subject teachers with a certified knowledge of the target language, such as CLIL teachers in secondary education.

The lack of research on OCF in CLIL classrooms (Dalton-Puffer \& Nikula, 2014) was what prompted Milla \& García Mayo (2014) to carry out another comparative study, where the corrective behavior of a CLIL and an EFL teacher as well as the uptake and repair patterns of a group of 30 intermediate level learners in different lessons were analyzed. The learners were 17-18 years old and belonged to an intact class in the second year of post-compulsory secondary education in a trilingual program (Spanish, language $\mathrm{X}$ and English), in which about 30\% of teaching time was devoted to each of the languages. Following a classroom observation procedure, the authors audio-recorded a total of 377 minutes of three CLIL lessons (Business Studies in English) and four EFL lessons. Besides the recording, the first author observed the lessons, which were analyzed using the COLT scheme as in Lyster \& Mori (2006), revealing that CLIL lessons were clearly oriented to meaning while EFL lessons were more form-oriented. This finding contrasts with Llinares \& Lyster's (2014) CLIL classrooms, where attention to form happened in a content/meaning-oriented setting. The reason may lie in the fact that in Milla \& García Mayo (2014) the CLIL teacher was a subject specialist with no specific training in language teaching, as is typical in secondary education in Spain. Conversely, primary school CLIL teachers are generally English language teachers that also teach subject matters in English. Therefore, it would be expected that CLIL secondary school teachers are less oriented to form and their lessons more focused on meaning, in a similar way to immersion classrooms.

The type of feedback provided by the teachers was classified into the six types identified by Lyster \& Ranta (1997): recasts, repetitions, clarification requests, elicitations, metalinguistic information and explicit correction. Milla \& García Mayo (2014) also examined which type of feedback promoted immediate uptake. The analysis of the CFEs in the two contexts revealed significant differences as to the amount of errors corrected by the EFL (72\%) and CLIL (53\%) teachers. The authors also found that the CLIL teacher used recasts almost exclusively while the EFL teacher used the whole spectrum of types, favoring explicit correction, elicitation, repetition, and metalinguistic feedback. Consider examples (2) and (3), which illustrate how the two teachers address a grammar error, by means of a recast in a CLIL classroom and by means of metalinguistic information and elicitation in an EFL classroom, respectively:

(2) Learner: the value it has when the company *start...

Teacher: ok, when the company starts ... and do you remember that

in order to calculate we have a simple formula? OK? It is...?

(addressing another learner). Do you remember? 
(3) Learner: something you did *give an enormous sense of achievement.

Teacher: the verb is OK, David, but not the tense. "Something you did", it's past so you cannot say give.

Learner: $\quad$ xxx I don't know.

Teacher: if the sentence is in the past, you will need a verb in the past, so?

Learner: gave.

In example 2, the CLIL teacher reformulates the grammar error, but he asks a question and continues with the lesson. Therefore, the learners might miss the correction, as they do not have an opportunity to react to the recast. According to the Noticing Hypothesis (Schmidt, 1990), noticing is essential for L2 learning. If learners miss the corrective intention of recasts, it is likely that they do not have an effect on their language learning process. In example 3 , we find a very explicit indication of where the error occurs and a second move by the teacher with an elicitation.

The findings in Milla \& García Mayo (2014) were in line with Lyster \& Mori's (2006), where the more form-oriented teachers (JFL) preferred prompts or didactic recasts and the more meaning-oriented teachers (FSL) used conversational recasts in a remarkably higher proportion with respect to other types. Milla \& García Mayo (2014) showed that, although the two teachers used different types of OCF, both used recasts very often and, therefore, no significant differences in the use of OCF between the two classrooms were reported, except for repetition and explicit correction, which were not used by the CLIL teacher. This lack of significance was attributed to the small amount of data that were obtained out of the recorded lessons. The authors were interested in unravelling the details of the CFEs occurring in the two contexts and carried out a qualitative analysis of OCF moves in order to explore the differences identified but not confirmed by the statistical analysis. The qualitative analysis revealed that the teachers not only provided different types of OCF but also used the types in a different way. Thus, the CLIL teacher made topic continuation moves after the correction, not allowing learners to react to OCF moves. On the contrary, the EFL teacher displayed a wider variety of OCF types and combined them, using what Lyster $\&$ Ranta (1997) termed as 'multiple feedback' (i.e. using several OCF types for the same error in the same move). Example 4, with data from our database, illustrates this phenomenon. The EFL teacher uses an explicit correction move and a metalinguistic cue, coded as explicit correction, following the conventions in Lyster \& Ranta's (1997) seminal study. This type of OCF move turns out to be really salient and therefore leads to uptake in most cases.

(4) Learner: *suits [swi.ts] and...

Teacher: not sweets [explicit correction]. Sweet is something that you eat and is full of sugar [metalinguistic cue]. Suits [su:ts] [explicit correction] yes? 
As for the results of the analysis of the uptake move, OCF led to higher rates of uptake in EFL lessons (82\%) than in CLIL (52\%). Regarding the learners' immediate response to the OCF types, it was found that there was a higher proportion of uptake after recasts and clarification requests in EFL and after elicitation and recasts in CLIL. Although these differences were not significant, the researchers reported that there was a tendency for learners to respond more positively to implicit types in a formoriented lesson and to explicit correction in the meaning-focused lessons of CLIL. These findings are in line with Lyster \& Mori (2006) and thus explained by the $\mathrm{CH}$. However, the authors acknowledged the limitations of their data and called for further research on OCF in the two settings, EFL and the under-researched CLIL context.

\section{The present study}

The main aim of this study is to explore CFEs in two different learning settings, namely CLIL and EFL, and assess the extent to which the type of instructional context affected the teachers' corrective behavior in terms of the amount and type of OCF chosen. The learners' uptake was also examined in both contexts as well as the effect that each of the OCF types had on their production. As mentioned above, in previous research Milla \& García Mayo (2014) reported few significant quantitative differences between the two contexts, which was probably due to the small dataset analyzed. However, interesting qualitative differences were observed. The current study has enlarged the database and has also analyzed two other EFL and CLIL teachers to discard the potential impact of individual teachers' idiosyncrasies on the results.

The following research questions were considered:

1. Is there a difference in the amount and types of OCF provided in CLIL and EFL classrooms?

2. Does type of error influence quantity and quality of OCF in each of the classrooms?

3. Does OCF lead to more uptake in CLIL or EFL classrooms? Do learners react differently to OCF types in the two classrooms?

\subsection{Participants}

Both the teachers and learners participating in this study belonged to a public high school. For the main study, two teachers volunteered: the CLIL teacher was a male with a background in Economics and 20 years of teaching experience, the last 
seven years of which he had used English as the language of instruction. He had a C1 level in the language according to the Common European Framework of Reference for Languages (Council of Europe, 2001). The EFL teacher was a female with 26 years of experience, with a degree in English Studies and several professional courses completed throughout her academic life.

The two participant teachers taught the same group of learners, 26 adolescents (17-18 year old, 14 female, 12 male students) in their second year of post-compulsory education with a proficiency level in English between B1 and B2 of the Council of Europe (2001), as attested by the Oxford Placement test administered to them. As suggested in previous research (Basturkmen, 2012), there was only one group of learners so that the teachers' behavior could be better compared.

Regarding the context, the participants belonged to a trilingual (Spanish, language X, English) programme, with approximately $30 \%$ of the time conducted in each of the languages. The EFL teacher, who met with the participants three hours per week, followed a communicative methodology but she also used a grammar book and put great emphasis on formal aspects of the language. Reading comprehension and writing were also very important as the participants had to take the university entrance exam at the end of their academic year. The methodology used by the CLIL teacher, who met with the participants four hours per week, was based on reading and discussing some notes and articles he himself provided, as well as carrying out practical exercises. The focus was mainly on content, also to prepare the students for the university entrance exam. More information about the lessons will be provided below.

Although the main corpus in the present study comes from the $2^{\text {nd }}$ year postcompulsory education teachers and learners, in order to discard a potential teacher effect, another pair of teachers were also recorded and the interaction data in their lessons was analysed. By observing another pair of teachers, we could assess whether the differences between the CLIL and EFL teachers in $2^{\text {nd }}$ year also existed in $1^{\text {st }}$ year as well and were not due to the $2^{\text {nd }}$ year teachers' idiosyncrasies. Several CLIL and EFL lessons were recorded in a $1^{\text {st }}$ year classroom in the trilingual programme at the same school. In the $1^{\text {st }}$ year group we also observed lessons from two subjects, EFL and CLIL. The EFL lessons were taught by a female teacher with 24 years of experience. The CLIL lessons (Science for the Contemporary World, a compulsory subject) were taught by another female teacher with 14 years of teaching experience. The participants were 25 16-year-old $1^{\text {st }}$ year post-compulsory education students ( 22 female and 3 male) with a B1 English proficiency as attested by the Oxford Placement Test (18 learners obtained B1, 6 B2, 1 C1). 


\subsection{Procedure}

In order to perform a comparative analysis of the CFEs occurring in EFL and CLIL contexts, we employed a classroom-observation methodology, a standard procedure in this type of studies (Llinares \& Lyster, 2014; Lochtman, 2007; Lyster \& Mori, 2006). Fifteen CLIL and twelve EFL lessons were observed and audio-recorded (a total of 22 hours 43 minutes). As in previous studies (Lyster \& Mori, 2006), we used the COLT scheme (Spada \& Fröhlich, 1995) to analyze the predominant orientation of the lessons, either to meaning or language form.

Besides this, 5 CLIL and 6 EFL lessons were recorded in the $1^{\text {st }}$ year $(8$ hours 5 minutes in total).

\subsection{Data coding and analysis}

The recorded data were transcribed following CHILDES (McWhinney, 2000) conventions and each of the moves in the CFEs was analyzed. First, the number and type of errors were examined in each of the classrooms, EFL and CLIL. Secondly, OCF and the use of the different OCF types were analyzed. The OCF types were the ones in Lyster \& Ranta's (1997) taxonomy, namely, recasts, clarification requests, repetitions, metalinguistic clues, elicitation and explicit correction. The teachers' use of the larger categories, reformulations (recasts and explicit correction) and prompts (clarification requests, repetitions, elicitation, metalinguistic cues, explicit correction) was also analysed. Finally, uptake of OCF and of the different types was compared in each of the classrooms. Data were transcribed and codified by the two authors independently and inter-rater reliability reached $98 \%$ agreement. Table 1 below displays the codes used for this analysis. 
Table 1: Transcription codes employed in the codification of the CFEs

\begin{tabular}{lll}
\hline CODE & MEANING & CATEGORY \\
\hline${ }^{*}$ L1 & UNSOLICITED L1 USE & \\
${ }^{*} \mathrm{G}$ & GRAMMAR ERROR & ERROR TYPES \\
${ }^{*} \mathrm{P}$ & PRONUNCIATION ERROR & \\
${ }^{*} \mathrm{~L}$ & LEXICAL ERROR & \\
\hline $\mathrm{NC}$ & NON-CORRECTED ERROR & \\
$\mathrm{RC}$ & RECAST & \\
$\mathrm{CL}$ & CLARIFICATION REQUEST & \\
$\mathrm{RP}$ & REPETITION & \\
$\mathrm{EL}$ & ELICITATION & \\
$\mathrm{ML}$ & METALINGUISTIC CUES \\
$\mathrm{EC}$ & EXPLICIT CORRECTION & \\
RF & REFORMULATION & \\
$\mathrm{PM}$ & PROMPT & UPTAKE TYPES \\
\hline UN & NO UPTAKE & \\
NR & NEEDS REPAIR & \\
SR & SELF-REPAIR & \\
Pe & PEER REPAIR & \\
\hline
\end{tabular}

Moreover, following Lyster \& Ranta's (1997) conventions, multiple feedback moves occurring in the same CFE were codified as single feedback moves. Thus, the following equivalences were used: Recast or Explicit correction together with Metalinguistic cues or Elicitation were codified as Explicit correction. Then, Metalinguistic cues together with Elicitation were codified as Elicitation. The analysis of multiple feedback moves was therefore carried out from a qualitative descriptive, as will be seen below.

Data were analyzed quantitatively by means of the $\mathrm{R}$ program ( $\mathrm{R}$ Development Core Team, 2008) and non-parametric tests (Fisher and Chi-square). Data were also analyzed qualitatively, with descriptions of CFEs that illustrate specific aspects that were not shown in the statistical analyses.

\subsection{Results}

In what follows, the results of the COLT analysis in the $2^{\text {nd }}$ year EFL and CLIL classrooms will be presented and the differences between the two classroom contexts 
highlighted. Regarding participant organization of the activities, in EFL lessons a teacher-fronted methodology was found more than half of the time (59\%), but group or pair activities and individual work of the learners also occurred. On the contrary, in CLIL lessons teacher-fronted activities were prevalent ( $94 \%$ of the total time) and only a very small amount of time was allowed for individual activities.

Regarding content focus, EFL lessons were divided into language and thematic content, with little time devoted to thematic content. As expected, CLIL lessons were focused on thematic content and no time at all was devoted to language content alone or in combination with thematic content. In the EFL lessons, the teacher and the learners worked together more than half of the time (about 59\%) and the learners worked with their peers and with texts the rest of the session, whereas in the CLIL classroom the lessons were controlled by the teacher most of the time. This means that in the EFL sessions there were more opportunities for learner interaction than in the CLIL lesson, which leads to learners having fewer opportunities for free production and repair of the errors, as we will see below. Finally, as for modality, EFL activities were more centred on oral skills, while in CLIL the focus was on both oral and written skills. As has been noted in previous research, learners' performance may vary dependent on context-related variables of the setting where they operate (Brown, 2016; Nassaji, 2020). The differences between the two classroom settings in our study are clear and, consequently, differences in CFEs are also expected.

After examining the lesson orientation in each of the contexts, CFEs were analyzed, starting with their first move, that of error. Learners showed a different behavior depending on the context: there was a larger number of errors in CLIL (562) than in EFL (171) and the type of errors also differed, with the unsolicited use of the L1 being a very frequent error type ${ }^{1}$ in CLIL and very scarce in EFL, as Table 2 below shows.

Table 2: Number and percentages of error types in EFL and CLIL

\begin{tabular}{lll}
\hline ERROR TYPE & EFL & CLIL \\
\hline L1 USE & $28(16.4 \%)$ & $392(69.8 \%)$ \\
GRAMMAR & $43(25.1 \%)$ & $45(8 \%)$ \\
PRONUNCIATION & $73(42.7 \%)$ & $104(18.5 \%)$ \\
LEXICAL & $27(15.8 \%)$ & $21(3.7 \%)$ \\
\hline TOTAL & 171 & 562 \\
\hline
\end{tabular}

1 We are aware that a moderate use of the $\mathrm{L} 1$ is no longer considered problematic in the second/foreign language classroom (Antón \& DiCamilla, 1998). However, as will be explained, the teachers in our study did consider L1 use an error and acted accordingly. That is the reason why unsolicited L1 use has been analyzed. 
Let us provide now the answers to the three research questions in the present study. The first question considered whether there could be a difference in the amount and types of OCF provided in the CLIL and the EFL classrooms. In order to answer it, data corresponding to the OCF provided by the $2^{\text {nd }}$ year CLIL and EFL teachers were analyzed. Based on the findings from previous studies (Milla \& García Mayo, 2014; Llinares \& Lyster, 2014; Lochtman, 2007; Lyster \& Mori, 2006), we expected to find significant differences regarding the amount and the types of OCF preferred by the EFL and the CLIL teachers. Specifically, more explicit types and prompts were expected in the EFL lessons, although recasts were expected to be the most frequently selected OCF type in both settings (Brown, 2016).

As explained above, in order to discard a potential teacher effect that could be influencing the results, data were collected from a second group of learners in their $1^{\text {st }}$ year of post-compulsory education at the same school with another pair of teachers, EFL and CLIL (Science in this case). We discarded the teacher effect since we obtained statistically similar results in the behavior of the EFL teachers in $1^{\text {st }}$ and $2^{\text {nd }}$ year as well as in the $1^{\text {st }}$ and $2^{\text {nd }}$ year CLIL teachers, both concerning proportion of errors corrected, analyzed by Chi-square tests (EFL $p=0.5833834$; CLIL $p=0.6121218)$ and OCF types, analyzed by Fisher tests (EFL $p=0.5508$; CLIL $p=0.05938$ ). We are aware that the similarities could be due to the fact that they belong to the same school but the data from the two teachers in $1^{\text {st }}$ year indicate that in the present study CLIL and EFL teachers behaved in a different manner, and these differences were not due to the idiosyncrasy of the individual teachers.

Regarding the results of $2^{\text {nd }}$ year classrooms, the proportion of errors corrected was analyzed. Graph 1 shows striking differences (confirmed by the Chi-square test, $p=0$ ) between the two teachers: the EFL teacher corrected more than $77 \%$ of errors (131 out of 171), while only $21 \%$ of them were corrected by the CLIL teacher ( 121 out of 562 errors).

Graph 1: Percentage of errors corrected and not corrected in EFL and CLIL

\section{EFL}

CLIL

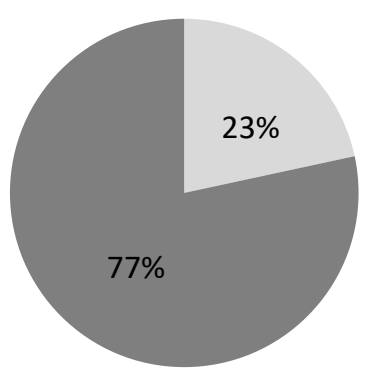

NON

CORRECTED

- CORRECTED

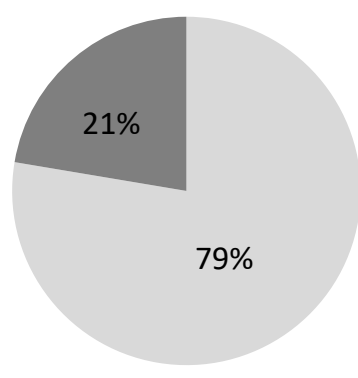

NON-

CORRECTED

CORRECTED 
Significant differences were also found in the use of the OCF types (Fisher test, $p=0$ ). While both teachers preferred recasts over the rest of the OCF types, as commonly found in other contexts (Sheen, 2004), our EFL teacher also resorted relatively frequently to prompts such as elicitation and, within reformulations, both recasts and explicit correction were used. Graph 2 illustrates these findings. As for the use of the larger categories, reformulations and prompts, no differences were found when comparing the two classrooms (Chi-square test, $p=.875$ ), since the proportion of the use of these categories was similar with reformulations being used much more frequently (107 cases in EFL, 68\%, and 84 in CLIL, 70\%) than prompts (50 cases in EFL, 32\%, and 36 in CLIL, 30\%). However, if OCF types are analyzed in detail, Graph 2 shows how the EFL teacher used both types of reformulations (both didactic recasts and explicit correction), while the CLIL teacher only resorted to recasts, which were of an implicit nature in his case.

Graph 2: Total number of OCF Types in EFL and CLIL Classrooms

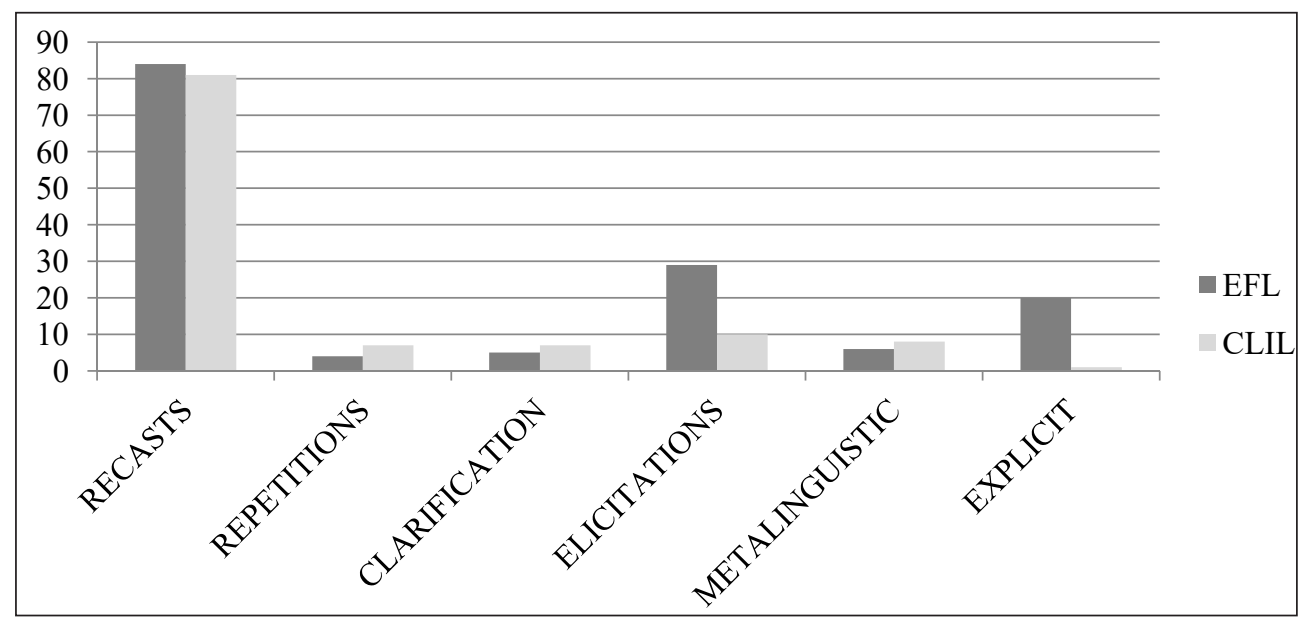

Considering recent findings on the potential benefits of the use of the L1 in SL and FL contexts and of translanguaging (García, 2019), analyses were carried out tallying lexical, grammar and pronunciation errors and not those related to L1 use. Significant differences were found as the teachers' proportion of correction $(p=0)$ as well as the use of OCF types ( $p=.007)$ were different in the two contexts.

Our second research question considered whether the type of error could influence the quantity and quality of OCF provided in each of the classrooms. Error type was hypothesized to affect the amount and type of OCF preferred by the teachers. Regarding the proportion of each error type corrected in the two classrooms, 
significant differences were found. Thus, the EFL teacher corrected $68 \%$ of grammar errors, whereas the CLIL teacher addressed $31 \%$. L1 use instances were addressed in $67 \%$ of the cases in EFL but $18 \%$ in CLIL. As for lexical errors, $70 \%$ and $81 \%$ of them received OCF in the EFL and the CLIL classrooms, respectively. The most striking contrast was found in pronunciation errors, which were corrected in $91 \%$ of the cases in EFL and 22\% in CLIL.

As for the OCF types used for each of the types of error, we predicted that recasts would be used to address phonological or lexical errors while prompts such as elicitation or metalinguistic cues would be chosen for grammar errors, as in previous research (Lyster \& Ranta, 1997; Lyster \& Mori, 2006). On the basis of the main focus of the lessons, we predicted that the EFL teacher would address grammar errors more often and by means of prompts, while the CLIL teacher was expected to show more concern for vocabulary errors and use more implicit types of OCF such as recasts. Our findings showed that the type of error had an impact on the OCF types used and significant differences were found both for each of the teachers (Chi-square test: CLIL $p=0 ; E F L p=0)$ as well as between the teachers, as explained in what follows.

Regarding grammar errors, Graphs 3 and 4 show that the CLIL teacher almost exclusively selected recasts to address this error type, while the EFL teacher used the whole spectrum of OCF types (Fisher test, $p=.002$ ). As for lexical errors, more variation can be observed in the OCF types preferred by the CLIL teacher, which is coherent with his meaning-oriented lessons. These types of meaning errors were more important for him and thus he addressed them more carefully. This concern for meaning over form is shown in the data and it was also expressed by the teacher himself in informal conversations and in a questionnaire he completed for a follow-up study (Milla \& García Mayo, in press). No significant differences can be reported in the use of OCF types for this type of error $(p=.073)$ in the two contexts. The use of OCF types was found to be significantly different regarding pronunciation errors ( $p=.047)$, given that, even though the preferred OCF type was recast, the EFL teacher also resorted to other OCF types such as explicit correction or elicitation, while the few instances of OCF for pronunciation errors in CLIL, were recasts except for one case of repetition. L1 use was mainly corrected by recasts by both teachers, with very little attention given to this type of error by the CLIL teacher in spite of the great amount of L1 use in this classroom. Significant differences were found regarding the teachers' behavior towards L1 use (Fisher test, $p=.032$ ). Analyses performed without tallying L1 use showed significant differences as well, both in the proportion of correction by each of the teachers of each of the error types (CLIL $p=0$; EFL $p=0$ ) and in the comparison between the two teachers $(p=.007)$. 
Graph 3: Total number of OCF types depending on error type in CLIL

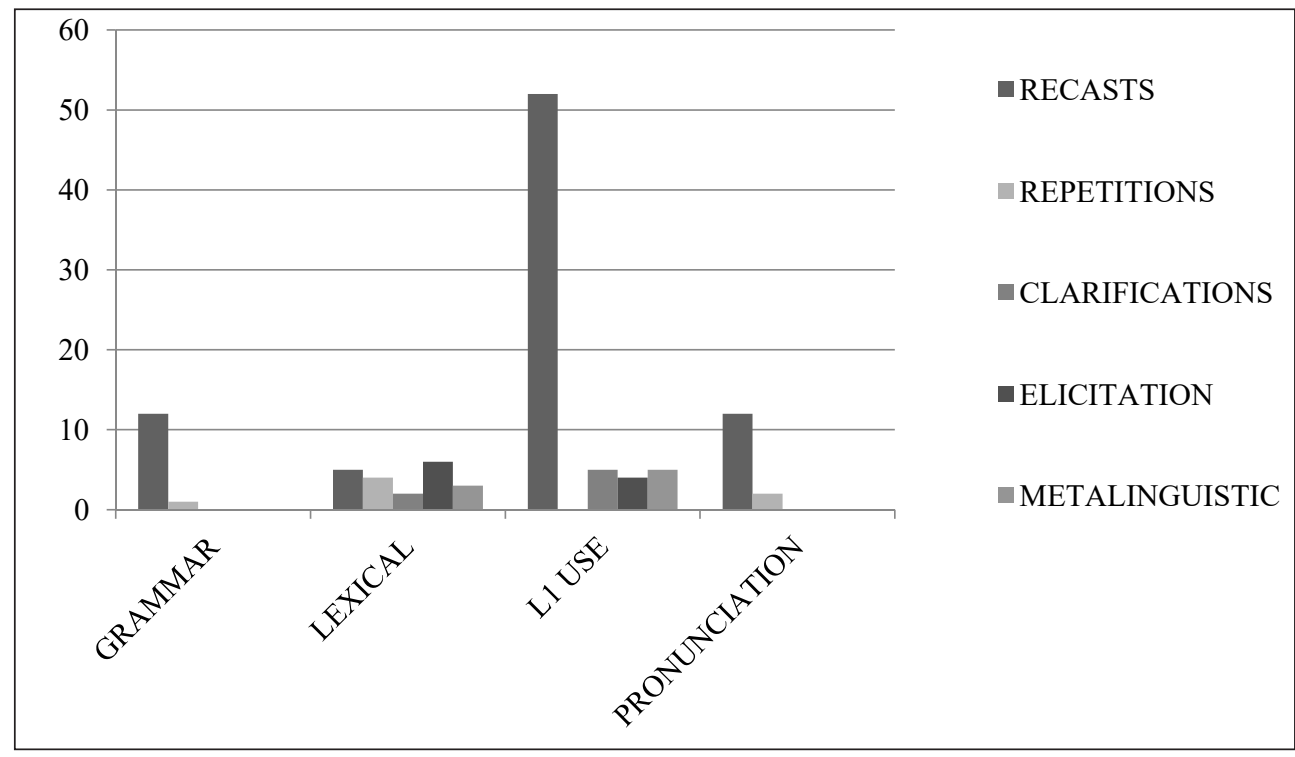

Graph 4: Total number of OCF types depending on error type in EFL

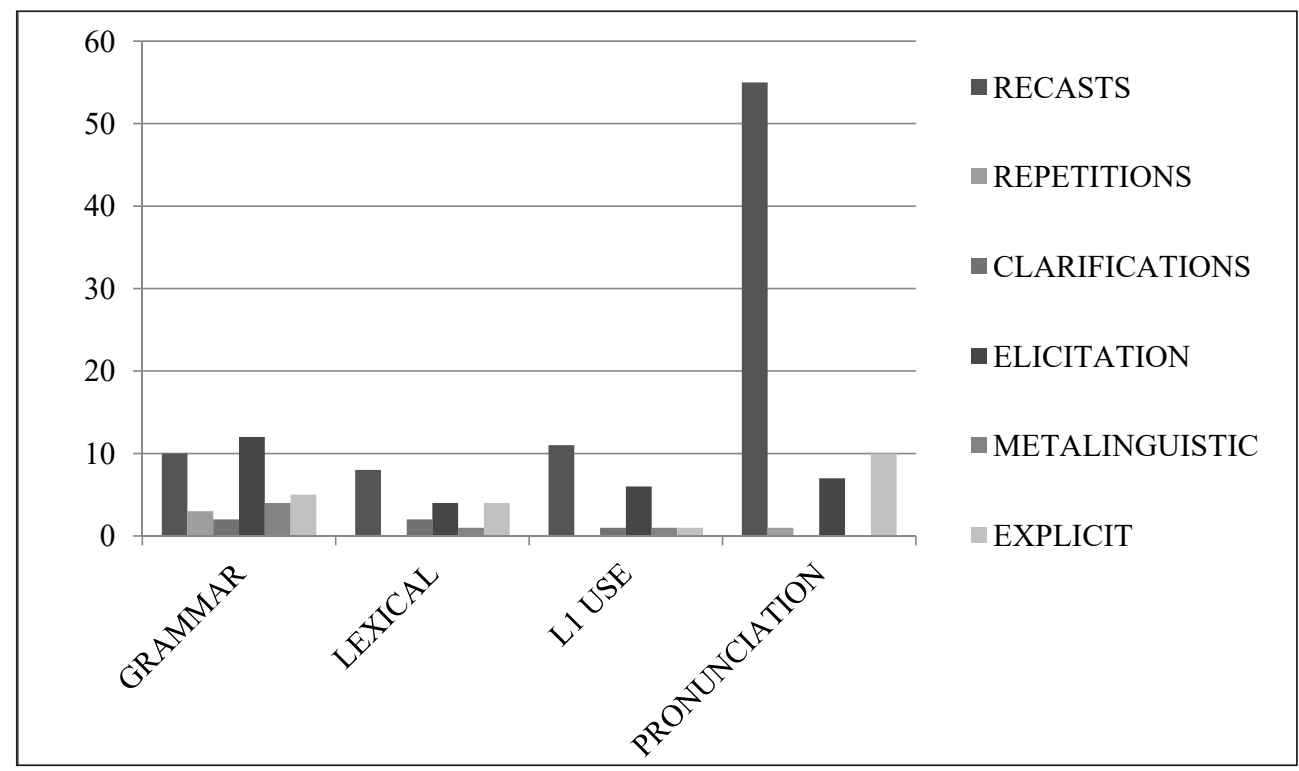

Data were triangulated by performing a qualitative analysis, which helped us to capture the nuances that were not reflected in the quantitative analyses, as had been previously done in comparative classroom observation studies (Milla \& García Mayo, 
2014). We found that the manner in which the teachers were using the types of OCF influenced the effect of these types, i.e. learners' uptake. For example, the EFL teacher used multiple feedback moves, which are said to lead to higher uptake, as explained above.

Looking at the data from a qualitative perspective we found that, although both teachers used recasts as the most frequent OCF type, these recasts were of a different nature. The EFL teacher used more explicit, shorter, and therefore more salient recasts, especially for pronunciation errors, as illustrated in example 5, while the recasts used by the CLIL teacher were more implicit or conversational in many cases. The CLIL teacher continued the topic after most of the recasts, preventing learners from acknowledging the correction or repairing the errors.

(5) Recast of an explicit type in EFL

Learner: $\quad$ a moth lands on your ${ }^{*}$ forehead [fว:head]...

Teacher: $\quad$ forehead [fว:hed].

Learner: $\quad$ forehead [fว:hed]. And then you hear laughter in the audience.

The CLIL teacher used a massive amount of recasts (71\%) and very rarely resorted to other types of OCF, unlike the EFL teacher, who made use of elicitation and metalinguistic information, as well a great number of recasts. The CLIL teacher's use of recasts is illustrated in example 6, where he reformulates a grammar error but then continues with the topic:

(6) Recast with topic continuation in CLIL

Learner: "between departments...

Teacher: $\quad \mathrm{OK}$, for example among the departments. When we meet all the departments, horizontal communication is in the same level of authority. OK, it is clear? That, we are going to see in a next day.

Finally, a remarkable number of CFEs with multiple feedback (12 out of 157 moves, $8 \%$ ) was found in EFL, whereas only one instance (out of $120,0.8 \%$ ) was identified in CLIL. As seen above, the EFL teacher corrected a large amount of the errors and used the whole spectrum of types, the most explicit types and prompts quite frequently, while the CLIL teacher corrected only a small proportion of the errors and used mainly recasts. In this sense, this difference in the use of multiple feedback moves was expected since this technique is typical of teachers who are more concerned with accuracy.

The third research question wondered whether OCF would lead to more uptake in the CLIL or the EFL classroom, and whether learners would react differently to 
various OCF types. On the basis of previous research, we expected higher rates of uptake in EFL due to the orientation to form in this type of lesson as well as the more salient OCF types provided. Graph 5 displays the findings of the Chi-square test, which showed that the learners' response was found to be different after OCF, with a significantly higher proportion of uptake $(p=0)$ in EFL (62\%) than in CLIL (32\%). This finding could not be observed in previous comparative studies because the groups of students compared were different. The types of uptake were also significantly different (Fisher test, $p=0$ ), as more self-repair was found in EFL (56 out of 152 CFEs, 37\%) than in CLIL (16 out of 116 CFEs, 14\%).

Graph 5: Total number of uptake and no uptake moves in EFL and CLIL classrooms

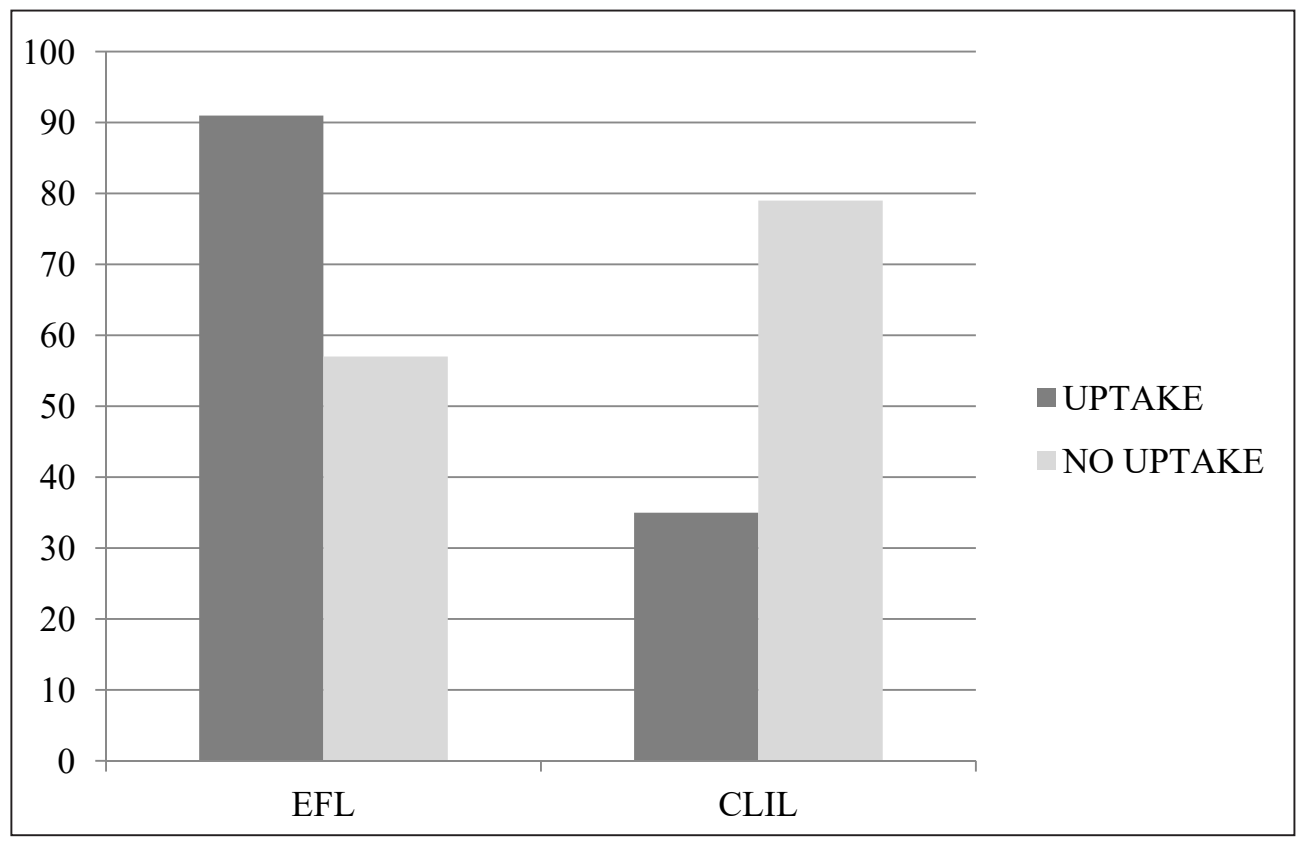

The analysis of the uptake of the different OCF types showed that there were higher rates of uptake after recasts, elicitations and explicit correction moves in EFL but only significant differences were found for recasts (Chi-square test, $p=0$ ). Consequently, reformulations were also found to lead to higher uptake in $\operatorname{EFL~}(p=0)$. Table 3 below displays these results: 
Table 3: Total number and percentages of uptake moves to the different OCF types in CLIL and EFL

$\begin{array}{lll}\text { OCF TYPES } & \text { EFL } & \text { CLIL } \\ \text { RECASTS } & 42(46.1 \%) & 5(14.4 \%) \\ \text { CLARIFICATION REQUESTS } & 5(5.5 \%) & 6(17.1 \%) \\ \text { REPETITIONS } & 4(4.4 \%) & 6(17.1 \%) \\ \text { METALINGUISTIC CUES } & 27(29.7 \%) & 10(28.6 \%) \\ \text { ELICITATION } & 4(4.4 \%) & 7(20 \%) \\ \text { EXPLICIT CORRECTION } & 9(9.9 \%) & 1(2.8 \%) \\ \text { REFORMULATIONS } & & 6(17.1 \%) \\ \text { PROMPTS } & 51(56 \%) & 29(82.9 \%) \\ & 40(44 \%) & 35 \\ \text { TOTAL UPTAKE MOVES } & 91 & \end{array}$

Regarding multiple feedback, we found that a combination of CF types led to successful repair in $67 \%$ of the cases (8 out of 12), mainly after elicitations. Uptake was high $(75 \%)$, probably because all multiple feedback types are by nature very explicit and, thus, salient.

\subsection{Discussion}

In this study we compared the behaviour regarding OCF of a CLIL teacher and an EFL teacher working with the same group of students and the students' reaction to the OCF provided. After the analysis of the lesson orientation in each of the classes, it was observed that EFL lessons were predominantly focused on language form, while CLIL lessons were oriented to meaning. The EFL teacher's behaviour was in line with the lesson orientation by showing great concern for learners' accuracy. She used a high proportion of CF and employed the whole spectrum of CF types with techniques such as multiple feedback, prompts, or explicit (didactic) recasts in order to promote learners' noticing of CF and self-repair, which she apparently achieved if one considers the high proportion of uptake in the EFL classroom. On the contrary, the CLIL teacher advocates for more implicit types of CF and addresses a very limited proportion of errors, which is coherent with the meaning-oriented context of his lessons. As seen above, a great deal of the errors in CLIL were related to the use of the L1, which the teacher himself considered inappropriate, as he often commented in the lessons. However, he chose not to address this type of error whenever learners were showing 
fluency or content was being developed. In summary, there was a significant difference in the amount of errors addressed by the EFL teacher in comparison with her CLIL counterpart. As for differences in the type of OCF provided, both teachers preferred the use of recasts but whereas the EFL teacher used both types of reformulations, namely, recasts and explicit correction, together with some prompts such as elicitation, the CLIL teacher overwhelmingly used implicit (conversational) recasts.

These findings are in line with previous studies in FL settings, where teachers are more focused on form (Lochtman, 2007; Lyster \& Mori, 2006) and use more explicit types of recasts and a higher amount of prompts. However, since there are no previous studies of OCF in secondary education levels in CLIL classrooms, we cannot establish a comparison with previous research. Llinares \& Lyster (2014) included CLIL classrooms at primary education level, where CLIL teachers are typically language specialists, and hence, more concerned with language accuracy than the CLIL teachers in secondary education, who are subject specialists with much less linguistic background. CLIL teachers in this study showed a similar behaviour to those in SL settings, where attention to fluency and content is preferred and OCF is less frequently used. If OCF is provided, recasts are their choice.

Regarding the issue of whether the type of error would have an impact on the quantity and quality of OCF, our findings showed that the most striking differences between the EFL and the CLIL teachers were related to how they addressed grammar, pronunciation and L1 errors. Thus, the EFL teacher paid much more attention to all those types of errors, especially to grammar (as is usually the case in FL settings, Brown (2016), whereas the CLIL teacher focused his concerns on lexical errors, again in line with the focus on meaning of his lessons. As for the type of OCF used for each of the errors, recasts were again the type of OCF type preferred by both teachers but there is an important difference: whereas the CLIL teacher used implicit (conversational) recasts, the EFL teacher used more explicit (didactic) recasts and, what is more, she displayed multiple feedback moves, other types of reformulation such as explicit correction, and prompts such as elicitation. Recasts were also preferred by the two teachers to address pronunciation errors, which has been found to be beneficial as the learners can make comparisons of the erroneous and the target form (Lyster \& Saito, 2010; Mackey, Gass \& McDonough, 2000; Sheen, 2006). The fact that recasts are the preferred type of OCF by both teachers is in line with previous research, as illustrated in Brown's (2016) meta-analysis of 28 studies. Brown reported that recasts accounted for $57 \%$ of all CF provided while prompts comprised $30 \%$.

As for OCF and learner uptake in the two types of lessons, the focus of our third research question, it seems that OCF was more effective in the EFL classroom where learners displayed a higher proportion of uptake than in the CLIL classroom. 
Significant differences regarding uptake in the two classrooms were only found for recasts, that is, learners benefitted more from the use of recasts in the EFL classroom than in the CLIL classroom. This is in line with Lyster \& Mori's (2006) Counterbalance Hypothesis, where they suggested that the use of more implicit types, such as recasts, are sufficient to obtain successful uptake in contexts where the learners' focus is on form, such as the EFL classroom in the present study. Besides, in more meaningoriented classrooms, more explicit and output pushing OCF types would be preferable, in order to obtain learners' attention, since their focus in this type of classrooms is not on language form. This may account for the relatively high success of prompts in our CLIL classrooms.

However, in spite of the salience of some CF types, a few instances of multiple feedback moves that were not acknowledged by the learners were attested. Multiple feedback moves are clearly salient and in our study most of them very explicit. Therefore, our findings suggest that explicitness is not a guarantee for uptake and that eliciting the correct form is more effective if teachers are seeking immediate repair. Consequently, given the present results, successful uptake would be obtained by prompts more than by recasts, particularly in meaning-oriented classrooms.

This study has reported that teachers correct differently in EFL and CLIL lessons, possibly influenced by the lesson orientation to form or meaning, respectively, as well as by the teachers' academic background, particularly, previous training in FL teaching. As shown above, learners act accordingly, displaying a different behaviour in EFL and CLIL lessons. In EFL they do not make as many errors and they hardly ever make use of their L1 while in CLIL lessons, where they are focused on content, they show less concern for language form and resort to their L1 very often in order to try to communicate ideas. We were able to find this different behaviour on the part of the learners depending on the type of setting they were immersed in, showing a clear influence of the context on all the participants of the CFEs. This change in the learners' behaviour could not have been analysed so precisely in previous studies, since the groups of learners in the comparisons belonged to different schools and even different countries (Llinares \& Lyster, 2014; Lyster \& Mori, 2006; Sheen, 2004).

\section{Conclusion}

The aim of the present study was to analyze CFEs in two learning contexts, EFL and CLIL, and explore the potential of this variable on the teachers' OCF choices as well as on the learners' reaction to those choices (uptake). One of the main findings reported is that the difference in lesson orientation in CLIL and EFL contexts influences not only the teachers' amount and types of OCF provided but also the learners' behavior, 
with different types and amount of errors and variations in the uptake depending on the lesson they are attending. Previous studies could not have analyzed this change in learners' behavior so precisely because the participants in the comparison groups belonged to different schools and sometimes to different countries. We have found that CFEs in the CLIL and EFL settings analyzed are different in number and in nature. Moreover, in this study we have found that, as predicted, CLIL classrooms in secondary education are oriented to meaning and not to form as was the case in primary education (Llinares \& Lyster, 2014), probably due to the teachers' lack of linguistic background in our setting, since they are subject specialists and not language teachers.

There are several pedagogical implications deriving from the findings of the study. First, we suggest that CLIL teachers should try to strike a balance between form and meaning in their lessons and they would probably benefit from training on this matter (Lo, 2019). That is, attention to form should be considered in CLIL settings as well if the aim of CLIL programs is to foster second language acquisition together with the acquisition of content knowledge. Moreover, we believe that collaboration between teachers and researchers should be encouraged. Teachers should be involved in research and informed of the findings, as they might be unaware of their own practices. Research findings should go beyond the limits of the academic world and reach educators and policy makers so that they can make informed decisions.

The study has shortcomings that should be acknowledged. It was located in a very specific geographical area and in a particular school, so our findings, however interesting they might be, have to be taken cautiously and cannot be generalized. Future research in secondary education CLIL should include other content areas and use a larger sample. Moreover, written CF should be considered in further research in order to see whether the differences between the contexts found in OCF can also be identified in the written mode. Finally, teachers' and learners' perspectives on CF should be explored in order to assess their potential impact on classroom behavior (Brown, 2009; Kartchava, 2016; Kartchava \& Ammar, 2014b).

\section{Acknowledgements}

The authors gratefully acknowledge funding from research grant IT904-16 from the Basque Government. We are extremely grateful to Botikazahar high school for participating in the study and especially to the teachers Susana Hernández and Iñaki Valencia for allowing data collection in their classrooms. 


\section{References}

Ammar, A. \& Spada, N. (2006). One size fits all? Recasts, prompts, and L2 learning. Studies in Second Language Acquisition, 28, 543-574.

Antón, M., \& DiCamilla, F.J. (1998). Socio-cognitive functions of L1 collaborative interaction in the L2 classroom. Canadian Modern Language Review, 54, 314-342.

Basturkmen, H. (2012). Review of research into the correspondence between language teachers' stated beliefs and practices. System, 40 (2), 282-295.

Bryfonski, L. \& Ma, X. (2020). Effects of implicit versus explicit corrective feedback on Mandarin tone acquisition in an SCMC learning environment. Studies in Second Language Acquisition, 42, 61-88.

Brown, A. (2009). Students' and teachers' perceptions of effective foreign language teaching: A comparison of ideals. The Modern Language Journal 93, 46-60.

Brown, D. (2016). The type and linguistic foci of oral corrective feedback in the L2 classroom: A meta-analysis. Language Teaching Research, 20(4), 436-458.

Council of Europe (2001). Common European Framework of Reference for Languages. Cambridge: Cambridge University Press.

Dalton-Puffer, C. (2011). Content and language integrated learning: from practice to principles. Annual Review of Applied Linguistics, 31, 182-204.

Dalton-Puffer, C. \& Nikula, T. (2014). Content and language integrated learning (guest editorial). The Language Learning Journal, 42(2), 117-122.

García, O. (2019). Translanguaging: A coda to the code? Classroom Discourse, 10, 369-373. Goo, J. (2012). Corrective feedback and working memory capacity in interaction-driven SL learning. Studies in Second Language Acquisition, 34, 445-474.

Goo, J. \& Mackey, A. (2013). The case against the case against recasts. Studies in Second Language Acquisition, 35, 127-65.

Gurzynski-Weiss, L. (2010). Factors Influencing Oral Corrective Feedback Provision in the Spanish Foreign Language Classroom: Investigating Instructor Native/Nonnative Speaker Status, Second Language Acquisition Education and Teaching Experience. Unpublished PhD dissertation, Georgetown University

Havranek, G. \& Cesnik, H. (2001). Factors affecting the success of corrective feedback. In S. Foster- Cohen \& A. Nizegorodzew (Eds.), EUROSLA Yearbook. Volume 1 (pp. 99-122). Amsterdam: Benjamins.

Kartchava, E. (2016). Learners' beliefs about corrective feedback in the language classroom: Perspectives from two international contexts. TESL Canada Journal/Review TESL du Canada, 33, 19-45. 
Kartchava, E. \& Ammar, A. (2014). The noticeability and effectiveness of corrective feedback in relation to target type. Language Teaching Research, 18 (4), 428-452.

Lasagabaster, D. \& Sierra, J.M. (2010). Immersion and CLIL in English: more differences than similarities. ELT Journal, 64, 376-395.

Li, S. (2014). Oral corrective feedback. ELT Journal Volume, 68 (2), 196-198.

$\mathrm{Li}, \mathrm{S}$. (2018). Corrective feedback in L2 speech production. In J. Liontas et al. (Eds.), The TESOL encyclopedia of English language teaching. London: Blackwell.

Llinares, A. \& Lyster, R. (2014). The influence of context on patterns of corrective feedback and learner uptake: a comparison of CLIL and immersion classrooms. The Language Learning Journal, 42 (2), 181-194.

Lo, Y. L. (2019). Development of the beliefs and language awareness of content subject teachers in CLIL: does professional development help? International Journal of Bilingual Education and Bilingualism, 22 (7), 818-823.

Lochtman, K. (2002). Oral corrective feedback in the foreign language classroom: how it affects interaction in analytic foreign language teaching. International Journal of Educational Research, 37, 271-283.

Lochtman, K. (2007). Die mündliche Fehlerkorrektur in CLIL und im traditionellen Fremdsprachenunterricht: Ein Vergleich. In C. Dalton-Puffer \& U. Smit (Eds.), Empirical Perspectives on CLIL Classroom Discourse (pp. 119-138). Frankfurt: Peter Lang.

Loewen, S. (2004). Uptake in incidental focus on form in meaning-focused ESL lessons. Language Learning, 54 (1), 153-188.

Long, M. H. (2015). Second language acquisition and task-based language teaching. Oxford, England: Wiley-Blackwell.

Lyster, R. (2002). Negotiation in immersion teacher-learner interaction. International Journal of Educational Research, 37, 237-253.

Lyster, R. (2004). Differential effects of prompts and recasts in form-focused instruction. Studies in Second Language Acquisition, 26 (3), 399-432.

Lyster, R. \& H. Mori (2006). Interactional feedback and instructional counterbalance. Studies in Second Language Acquisition, 28 (2), 269-300.

Lyster, R., \& Ranta, L. (1997). Corrective feedback and learner uptake: Negotiation of form in communicative classrooms. Studies in Second Language Acquisition, 19, 37-66.

Lyster, R. \& Saito, K. (2010). Oral feedback in classroom SLA. A meta-analysis. Studies in Second Language Acquisition, 32, 265-302.

Lyster, R., Saito, K., \& Sato, M. (2013). Oral corrective feedback. Language Teaching, 46 (1), 1-40. 
Mackey, A. \& Goo, J. (2007). Interaction research in SLA: A meta-analysis and research synthesis. In A. Mackey (Ed.), Conversational Interaction in Second Language Acquisition (pp. 407-472). Oxford: Oxford University Press.

Mackey, A., Gass, S., \& McDonough, K. (2000). How do learners perceive interactional feedback? Studies in Second Language Acquisition, 22, 471-497.

McWhinney, B. (2000). The CHILDES Project: Tools for Analyzing Talk. $3^{\text {rd }}$ edition. Mahwah, N. J. Lawrence Earlbaurn Associates.

Milla, R. \& García Mayo, M. P. (2014). Corrective feedback episodes in oral interaction: A comparison of a CLIL and an EFL classroom. International Journal of English Studies, 14(1): 1-20.

Milla, R. \& García Mayo, M. P. (in press). Teachers' and learners' beliefs about corrective feedback compared with classroom behaviour in CLIL and EFL. In Talbot, K., Mercer, S., Gruber, M.-T. \& Nishida, R. (Eds.), The Psychological Experience of Integrating Language and Content. UK: Multilingual Matters.

Mori, R. (2002). Teachers' beliefs and corrective feedback. JALT Journal, 24 (1), 48-69.

Nassaji, H. (2020). Assessing the effectiveness of interactional feedback for L2 acquisition: Issues and challenges. Language Teaching, 53, 3-28.

Nassaji, H. \& Kartchava, E. (eds.). The Cambridge Handbook of Corrective Feedback in Language Learning and Teaching. Cambridge: Cambridge University Press (forthcoming).

Oliver, R. \& Grote, E. (2010). The provision and uptake of different types of recasts in child and adult ESL learners: What is the role of age and context? Australian Review of Applied Linguistics, 33 (3): 26.1-26.22.

Panova, I. \& Lyster, R. (2002). Patterns of corrective feedback and uptake in an adult ESL classroom. TESOL Quarterly, 36, 573-595.

Pérez Cañado, M. L. (2012). CLIL research in Europe: Past, present and future. International Journal of Bilingual Education and Bilingualism, 15, 315-341.

R Development Core Team (2014). R: A Language and Environment for Statistical Computing. R Foundation for Statistical Computing, Vienna, Austria.

Russell, V.J. \& Spada, N. (2006). The effectiveness of corrective feedback for second language acquisition: A meta-analysis of the research. In J. Norris \& L. Ortega (Eds.), Synthesizing Research on Language Learning and Teaching (pp. 133-164). Amsterdam: John Benjamins.

Saito, K. (2013). The acquisitional value of recasts in instructed second language speech learning: Teaching the perception and production of English / $/$ / to adult Japanese learners. Language Learning, 63 (3), 499-529. 
Saito, K. \& Lyster, R. (2012). Effects of form-focused instruction and corrective feedback on L2 pronunciation development of / I / by Japanese learners of English. Language Learning, 62, 595-633.

Schmidt, R. (1990). The role of consciousness in L2 learning. Applied Linguistics, 11, 129-158.

Sheen, Y. (2004). Corrective feedback and learner uptake in communicative classrooms across instructional settings. Language Teaching Research, 8(3), 263-300.

Sheen, Y. (2006). Exploring the relationship between characteristics of recasts and learner uptake. Language Teaching Research, 10, 361-392.

Sheen, Y. (2011). Corrective Feedback, Individual Differences and Second Language Learning. New York: Springer.

Spada, N. \& Fröhlich, M. (1995). COLT. Communicative Orientation of Language Teaching Observation Scheme: Coding Conventions and Applications. Sydney, Australia: National Centre for English Language Teaching and Research.

Tedick, D. J. \& Cammarata, L. (2012). Content and language integration in K-12 contexts: Learner outcomes, teacher practices and stakeholder perspectives. Foreign Language Annals, 45 (1), 28-53.

Yang, J. (2016). Learners' oral corrective feedback preferences in relation to their cultural background, proficiency level and type of error. System, 61, 75-86.

Yang, Y. \& Lyster, R. (2010). Effects of form-focused practice and feedback on Chinese EFL learners' acquisition of regular and irregular past tense forms. Studies in Second Language Acquisition, 32, 235-263.

Yilmaz, Y. (2012). The relative effects of explicit correction and recasts on two target structures via two communication modes. Language Learning, 62, 1134-1169. 